\title{
A typical working-day breakfast among children, adolescents and adults belonging to the middle and upper socio-economic classes in Mumbai, India - challenges and implications for dietary change
}

\author{
Malathi Sivaramakrishnan* and Vidya Kamath \\ Research Centre, Nirmala Niketan College of Home Science, 49 New Marine Lines, Mumbai - 400 020, India
}

Submitted 12 July 2011: Final revision received 16 February 2012: Accepted 23 April 2012: First published online 30 May 2012

\begin{abstract}
Objective: Breakfast has been linked to several aspects of health, yet breakfast skipping is rampant across the globe. Studies in India have focused mostly on children. Hence the present study examined breakfast behaviour across different age and gender groups.

Design: Cross-sectional sample, purposive sampling. Nutrient intakes of the participants derived from $24 \mathrm{~h}$ dietary recall and $3 \mathrm{~d}$ breakfast record data were compared with RDA values prescribed by the Indian Council of Medical Research using Student's $t$ test, with $P<0.05$ taken to indicate significance.

Setting: Mumbai, India.

Subjects: Participants ( $n$ 1027) aged 8 years and above.

Results: Nutritional adequacy of the breakfast meal and that of the day's diet were the main outcome measures. Eighty-one per cent of the participants had a nutritionally inadequate breakfast. Intakes of $\mathrm{Fe}$ and dietary fibre were notably low. Consumption of just milk or milk plus a milk food-based drink among schoolchildren (49\%) and increased breakfast skipping among adolescents (37\%) were seen.

Conclusions: The study identifies both irregularities and/or nutritional inadequacies with respect to the breakfast meal. Age- and gender-specific challenges in breakfast behaviour need to be addressed. Development of 'nutrient-dense' breakfast foods that can be prepared easily, school breakfast programmes and education on the importance of breakfast are the needs of the hour.
\end{abstract}

Keywords Breakfast intake Breakfast skipping Breakfast behaviour
There is ample evidence for the health benefits of a regular, healthy breakfast comprising fibre-rich cereal grains, fruits and low-fat dairy. However, a noticeable dietary change in recent times has been one of meal skipping, notably the skipping of the breakfast meal. This phenomenon of skipping the first meal of the day has been documented by several studies across the globe ${ }^{(1-5)}$. In the Indian context, most published literature has been on children and studies have focused on the impact of skipping breakfast on their cognitive performance ${ }^{(6,7)}$. There is a dearth of scientific data from India on the breakfast consumption pattern across different age/gender groups. Moreover, Indian diets are unique in terms of their regional diversity in composition. Typical breakfast foods are very often home-made and vary not only across region, but also across different groups of people living in each region. Mumbai is a typical cosmopolitan Indian city. The present study therefore examined the breakfast consumption pattern among children, adolescents and adults living in Mumbai. The nutritional adequacy of the breakfast meal and that of the day's diet were evaluated. The specific objectives of the study were to assess (i) the nutritional adequacy of the breakfast meal in terms of percentage contribution to the RDA for energy and other nutrients and (ii) the nutritional adequacy of the day's intake of nutrients in terms of percentage contribution to the RDA.

\section{Methodology}

\section{Study design}

A cross-sectional sample of 1027 healthy volunteers living across Mumbai aged 8 years and above was selected using the purposive sampling technique. A cut-off of 8 years was used since children aged 8 years and above are able to give an 'unassisted $24 \mathrm{~h}$ recall' ${ }^{(8)}$. However, information provided by the younger children was crosschecked by talking to the mothers. 


\section{Participants and recruitment}

Data were collected from participants living in different suburban stations along the two zonal railways of Mumbai, i.e. Western Railway and Central Railway, in such a way that included participants living in the East, West, South, North and Central Mumbai areas. Background information on age, gender, medical history, education and occupation of the participants was collected using a questionnaire. Only participants belonging to the SEC A1, SEC A2, SEC B1 and SEC B2 categories (representing the middle and upper socio-economic classes) were selected for the study. This categorization is based on Kuppuswamy's socio-economic status scale ${ }^{(9)}$ that is widely used for socio-economic assessment in India. Pregnant or lactating women, individuals on insulin or specific therapeutic diets and individuals with critical illness were not included in the study as their dietary patterns are likely to be different.

The study was approved by the Ethics Committee of Nirmala Niketan College of Home Science, Mumbai. Informed consent was taken from the participant or from the mother for very young participants before recruiting them for the study.

\section{Dietary assessment}

A $24 \mathrm{~h}$ dietary recall for a typical weekday was taken to assess the nutrient intakes of each participant using a standard protocol. It was ensured that the day of recall was not a holiday and that a typical working day schedule was being followed on that day. The $24 \mathrm{~h}$ recall consisted of listing all foods consumed on the day previous to the day of the interview. The data were collected and recorded by trained research assistants in the field of dietetics, who were trained to probe for information so that it could be effectively translated into nutrient content. Standard cups and sample cut-outs of Indian bread (rotis) were used in data collection to estimate the portion sizes accurately. The thickness, length and diameter were recorded for food items like sweets, cakes and other foods wherever it was relevant. Quantities of food-based supplements, sugar, sauces, chutneys, pickles and butter were recorded in spoon measures. For all home-made preparations, specific information on the ingredients and method of preparation was gathered to get a precise picture of the participant's food/nutrient intake. In the case of processed foods, the brand names, size and/or price of the pack were procured from the participant to judge the exact quantities consumed. In the case of children, information provided by the child was supplemented with information provided by the mother, wherever required. Since the primary focus of the paper was on breakfast, dietary data on breakfast intakes alone were also collected for three working days and the average intake computed. A breakfast record sheet with an illustrated sample of the breakfast record was given to the participants and the procedure for filling it out was explained by the research assistants. The record sheets, duly filled, were collected after verification for completeness of data entry by the research assistants.

A computerized database of standardized Indian recipes (internal software) and the Indian food composition tables $^{(10)}$ were used to convert the dietary data into nutrient consumption data. Intakes of energy, protein, fat, minerals (Ca and $\mathrm{Fe}$ ), vitamins (A, C, thiamin, riboflavin and niacin) and dietary fibre were calculated for breakfast (using $3 \mathrm{~d}$ breakfast record data) and for the day's diet (using $24 \mathrm{~h}$ recall data). All nutrient calculations were based on the nutritive value of raw ingredients per $100 \mathrm{~g}$ edible portion as available in the Indian food composition tables. The questionnaire method was used to generate additional information from the participants on breakfast behaviour.

\section{Definition of the breakfast meal}

For the purpose of the present study, the definition of the breakfast meal was arrived at keeping in mind the following facts: (i) the dietary recall was taken on a typical working day; and (ii) in urban India today, most schools in cities like Mumbai operate on a double shift in school timings wherein the morning shift typically starts at 07.30 hours and ends at 12.30 hours, whereas the afternoon shift starts at 13.00 hours and ends at 18.00 hours. Based on these criteria, 'breakfast' in the present study was defined as:

1. Any food item solid or liquid consumed before 09.00 hours for adults and for adolescents and children attending the morning school.

2. Any food item solid or liquid consumed before 11.00 hours for adolescents and children attending the afternoon school.

\section{Criterion of a nutritionally adequate breakfast}

The term 'nutritionally adequate breakfast' used in the present paper refers to breakfast that provides at least $25 \%$ of the RDA for energy.

\section{Data analyses}

The data were transferred to the SPSS for Windows statistical software package version 16.0 (SPSS Inc., Chicago, IL, USA). Descriptive statistics like mean and standard deviation were calculated for each age group and gender. Student's $t$ test at $P<0.05$ was used to compare the nutritional intake of participants with the RDA for that particular age and gender group prescribed by the Indian Council of Medical Research (ICMR) ${ }^{(11)}$.

\section{Results}

\section{Sample characteristics}

Table 1 presents the distribution of the study population according to age. The overall sample consisted of $46 \%$ male participants and $54 \%$ female participants. Figure 1 represents the linguistic distribution of the study population. 
Table 1 Distribution of the study population according to age; children, adolescents and adults ( $n$ 1027, aged 8 years and above) belonging to the middle and upper socio-economic classes in Mumbai, India

\begin{tabular}{|c|c|c|c|c|c|}
\hline \multirow[b]{2}{*}{ Age group } & \multicolumn{2}{|c|}{ Males } & \multicolumn{2}{|c|}{ Females } & \multirow[b]{2}{*}{ Total number of participants } \\
\hline & $n$ & $\%$ & $n$ & $\%$ & \\
\hline Children (8-12 years) & 90 & 52 & 83 & 48 & 173 \\
\hline Adolescents (13-15 years) & 103 & 60 & 68 & 40 & 171 \\
\hline Adolescents ( $16-18$ years) & 33 & 16 & 170 & 84 & 203 \\
\hline Young adults ( $18-40$ years) & 118 & 49 & 125 & 51 & 243 \\
\hline Older adults ( $\geq 40$ years) & 121 & 51 & 116 & 49 & 237 \\
\hline Sample size & & & & & 1027 \\
\hline
\end{tabular}

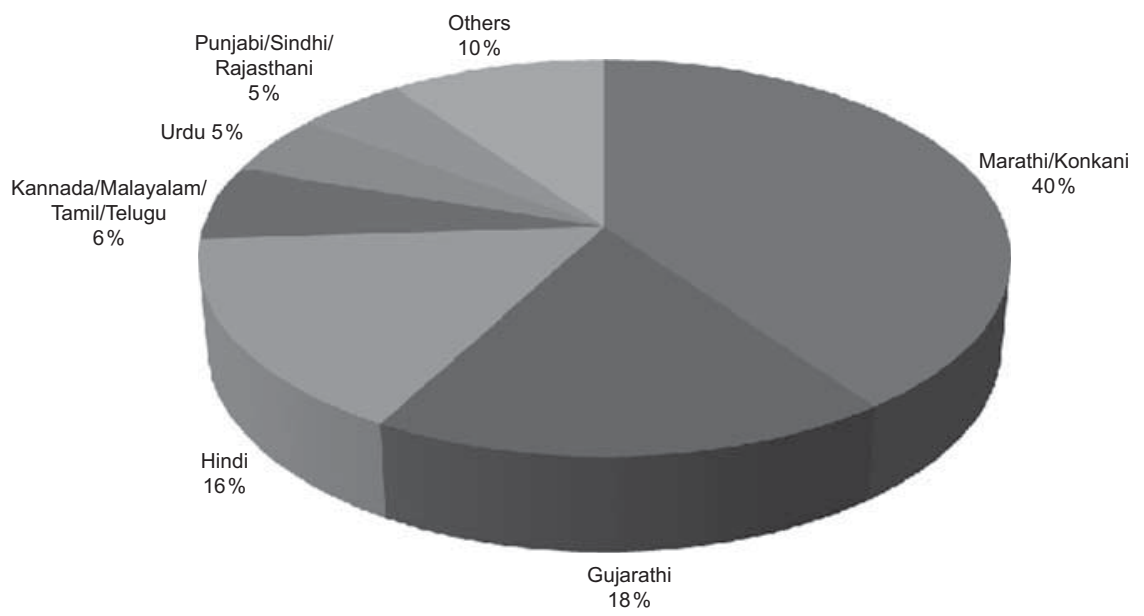

Fig. 1 Linguistic profile of the study population; children, adolescents and adults ( $n$ 1027, aged 8 years and above) belonging to the middle and upper socio-economic classes in Mumbai, India

The total sample of school-going participants (children aged 8-12 years; adolescents aged 13-15 years) consisted of $67 \%$ of morning school students and $33 \%$ of afternoon school students.

\section{Nutritional adequacy of the breakfast meal}

The study participants were divided into four groups based on the contribution of breakfast towards the day's RDA for energy, as follows.

1. Group I: $0 \%$ of the RDA (breakfast skippers).

2. Group II: $1 \%$ to $\leq 15 \%$ of the RDA (inadequate breakfast consumers).

3. Group III: $>15 \%$ to $\leq 25 \%$ of the RDA (inadequate breakfast consumers).

4. Group IV: $>25 \%$ of the RDA (adequate breakfast consumers).

The data (Fig. 2) revealed that while 16\% of the participants were skipping breakfast, $81 \%$ of the participants were having some liquid or solid food at breakfast but it was meeting $\leq 25 \%$ of the day's RDA for energy. Furthermore, $64 \%$ of the study population were consuming $\leq 15 \%$ of the day's RDA for energy at breakfast.

When the nutritional adequacy of breakfast was examined among the different age groups (Table 2) it was seen that, although there was not much breakfast skipping among children (8-12 years) and the younger adolescents (13-15 years), the percentage of participants consuming a meal providing $\leq 15 \%$ of the day's energy was very high (64\% for 8-12-year-olds; 79\% for 13-15-year-olds). Similarly, very few participants in these two age groups were having a substantial breakfast providing $>25 \%$ of the day's RDA for energy.

A further examination of the specific contents of the breakfast meal among the school-going participants revealed that $49 \%$ of the children (8-12 years) and $40 \%$ of the young adolescents (13-15 years) were going to school with a glass of milk or milk plus a milk food-based drink (i.e. milk/malt-based health beverage). A few children, mostly girls, were found to be having some traditional Indian breakfast foods like khakra/poha/bhakri/parata or other breakfast foods like omelette/sandwiches/breakfast cereal/biscuits with milk. However, the portion size was such that majority of them could meet only $\leq 15 \%$ of the day's energy through this meal.

The breakfast consumption data among the collegegoing adolescents (16-18 years) in the study population revealed a different pattern. It was seen that a greater percentage of them (37\%) were actually skipping breakfast. Data generated on the nutritional adequacy of 


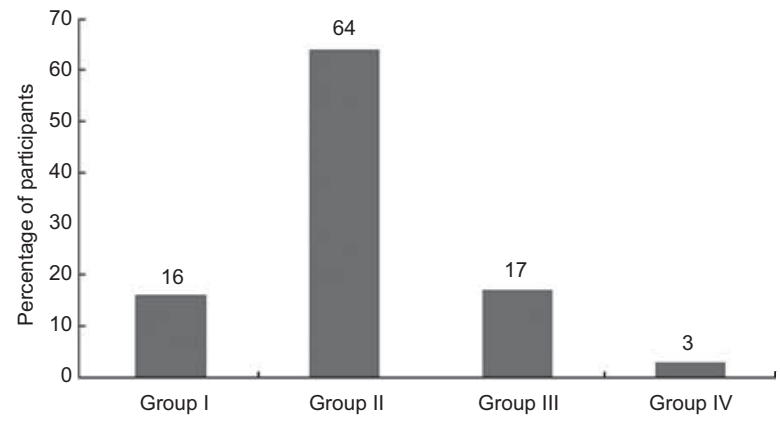

Fig. 2 Distribution of the study population based on the nutritional adequacy of breakfast (Group I, $0 \%$ of the RDA for energy (breakfast skippers); Group II, $1 \%$ to $\leq 15 \%$ of the RDA for energy (inadequate breakfast consumers); Group III, $>15 \%$ to $\leq 25 \%$ of the RDA for energy (inadequate breakfast consumers); Group IV, $>25 \%$ of the RDA (adequate breakfast consumers)); children, adolescents and adults ( $n$ 1027, aged 8 years and above) belonging to the middle and upper socioeconomic classes in Mumbai, India. RDA as given by the Indian Council of Medical Research ${ }^{(11)}$

Table 2 Distribution of the study population according to the four groups based on nutritional adequacy of breakfast; children, adolescents and adults ( $n$ 1027, aged 8 years and above) belonging to the middle and upper socio-economic classes in Mumbai, India

\begin{tabular}{|c|c|c|c|c|c|c|c|c|}
\hline \multirow[b]{2}{*}{ Age group } & \multicolumn{2}{|c|}{ Group I } & \multicolumn{2}{|c|}{ Group II } & \multicolumn{2}{|c|}{ Group III } & \multicolumn{2}{|c|}{ Group IV } \\
\hline & $n$ & $\%$ & $n$ & $\%$ & $n$ & $\%$ & $n$ & $\%$ \\
\hline $8-12$ years & 4 & 2 & 111 & 64 & 48 & 28 & 10 & 6 \\
\hline $13-15$ years & 12 & 7 & 135 & 79 & 21 & 12 & 3 & 2 \\
\hline $16-17$ years & 75 & 37 & 116 & 57 & 10 & 5 & 2 & 1 \\
\hline $18-40$ years & 51 & 21 & 136 & 56 & 51 & 21 & 5 & 2 \\
\hline$\geq 40$ years & 26 & 11 & 154 & 65 & 43 & 18 & 14 & 6 \\
\hline
\end{tabular}

Group I, $0 \%$ of the RDA for energy (breakfast skippers); Group II, $1 \%$ to $\leq 15 \%$ of the RDA for energy (inadequate breakfast consumers); Group III, $>15 \%$ to $\leq 25 \%$ of the RDA for energy (inadequate breakfast consumers); Group IV, $>25 \%$ of the RDA (adequate breakfast consumers.

RDA as given by the Indian Council of Medical Research ${ }^{(11)}$.

the breakfast meal among adults revealed a pattern very similar to the overall sample. Breakfast skipping, however, was significantly lower $(P \leq 0 \cdot 05)$ among the older adults $(11 \%$ among those aged $\geq 40$ years $v .21 \%$ among those aged 18-40 years; Table 2).

\section{Breakfast intake of otber nutrients}

Along with the energy content, the average intake of protein, fat, minerals ( $\mathrm{Ca}$ and $\mathrm{Fe}$ ), vitamins (A, C, thiamin, riboflavin and niacin) and dietary fibre for the entire sample was calculated as a percentage of the day's RDA (as given by $\mathrm{ICMR}^{(11)}$ ) for each age/gender group (Table 3). The mean intakes of energy, protein, fat, dietary fibre, $\mathrm{Fe}$, vitamin A, thiamin, riboflavin and niacin in the breakfast meal were significantly lower $(P<0.05)$ than $25 \%$ of the day's RDA. The only groups where statistical significance did not emerge were the 18-40-year-old males and $\geq 40$-year-old males and females for fat; and the 16-17-year-old males for vitamin A and riboflavin. Intakes were significantly higher than $25 \%$ of the RDA for

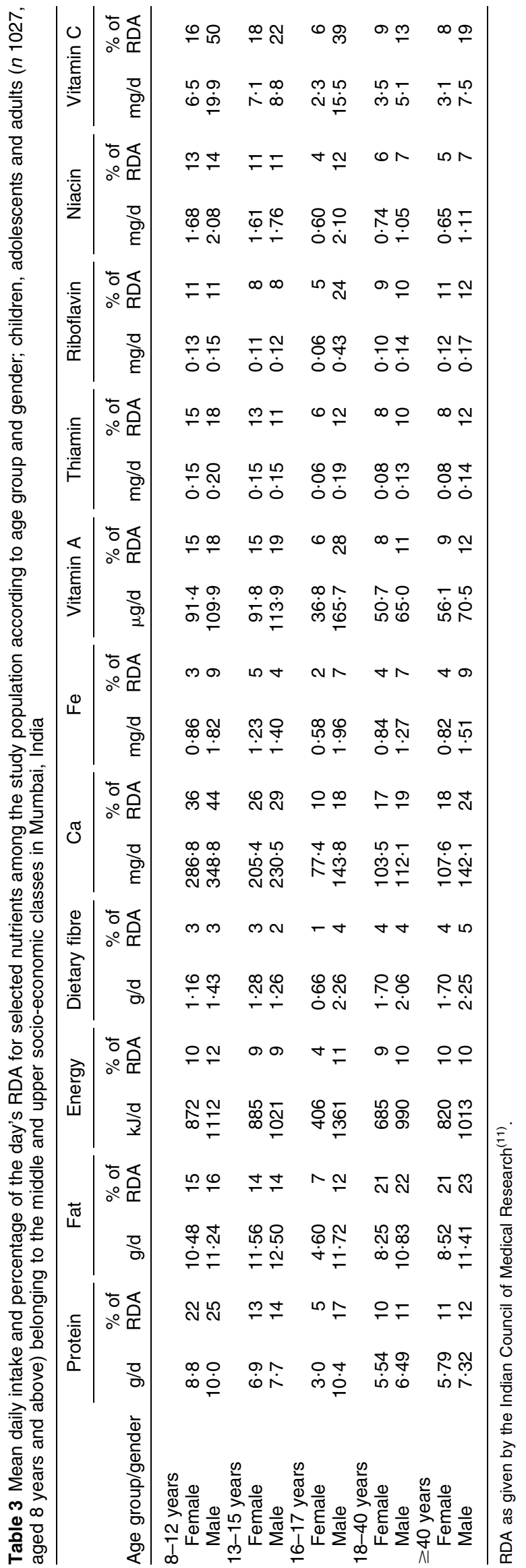


protein among the 8-12-year-old children; and for $\mathrm{Ca}$ among the 8-12-year-old children and 13-15-year-old adolescent boys. Intakes of vitamin $\mathrm{C}$ varied across groups being significantly higher than $25 \%$ of the RDA only for 8-12-year-old boys. Intakes of Fe were significantly low in all age groups, meeting on an average only $4 \%$ of the day's RDA. The average fibre intake from breakfast across age groups was in the range of 1 to $2 \mathrm{~g} / \mathrm{d}$ compared with the recommended fibre intake of 38 to $61 \mathrm{~g} / \mathrm{d}^{(11)}$.

\section{Nutritional adequacy of the day's diet}

The nutrient content of the whole day's diet was calculated to evaluate whether the inadequacies of the breakfast meal were being made up by the rest of the day's diet. The nutrient inadequacies at the breakfast meal were not being made up during the rest of the day. Figure 3 provides the mean intakes of energy, protein, fat, dietary fibre, $\mathrm{Ca}, \mathrm{Fe}$, vitamin $\mathrm{C}$ vitamin $\mathrm{A}$, thiamin, riboflavin and niacin as a percentage of the RDA for the entire sample. The day's intakes of energy, dietary fibre, riboflavin, niacin and $\mathrm{Fe}$ were significantly lower than the RDA $(P<0 \cdot 05)$. The only group where statistical significance did not emerge was for energy among the 8-12-year-old boys. Intakes of $\mathrm{Ca}$ and vitamin $\mathrm{C}$ were significantly higher than the RDA $(P<0.05)$ in all groups except the adolescents (13-15 years; $16-17$ years) for Ca intake. However, it is important to realize that the results for the day's intake of nutrients are based on $24 \mathrm{~h}$ recall data and could be influenced by the consumption of 'nutrient-rich sources' on the day of recall. Protein intake was found to be significantly higher than the RDA only among 8-12-year-olds (males and females). Vitamin A intake varied across age groups. Fat intake was found to be significantly higher among adults (18-40 years; $\geq 40$ years), 8-12-year old boys and 13-15-year-old girls.

\section{Reasons for breakfast skipping}

Not being hungry and lack of time for consuming breakfast emerged as the most frequently stated reasons for breakfast skipping. Boredom, stress, being tired and necessity for travel were some of the other reasons cited.

\section{Discussion}

There is a lot of ambiguity in the definition of the term 'breakfast' in the literature. While Preziosi et al. ${ }^{(12)}$ defined breakfast as the first eating occasion involving a solid food or a beverage that occurred after waking and Yang et al. ${ }^{(13)}$ referred to it as food eaten before 09.00 hours irrespective of the meal content, Timlin and Pereira ${ }^{(14)}$ defined it as:

the first meal of the day, eaten before or at the start of the daily activities (errands, travel, work) within $2 \mathrm{~h}$ of waking, typically no later than $10.00 \mathrm{a} . \mathrm{m}$. and of a caloric value between $20-35 \%$ of the daily energy needs.

Breakfast in the present study refers to any food (solid/ liquid/or both) consumed either (i) prior to 09.00 hours for adults and for adolescents and children attending morning school or (ii) prior to 11.00 hours for adolescents and children attending afternoon school.

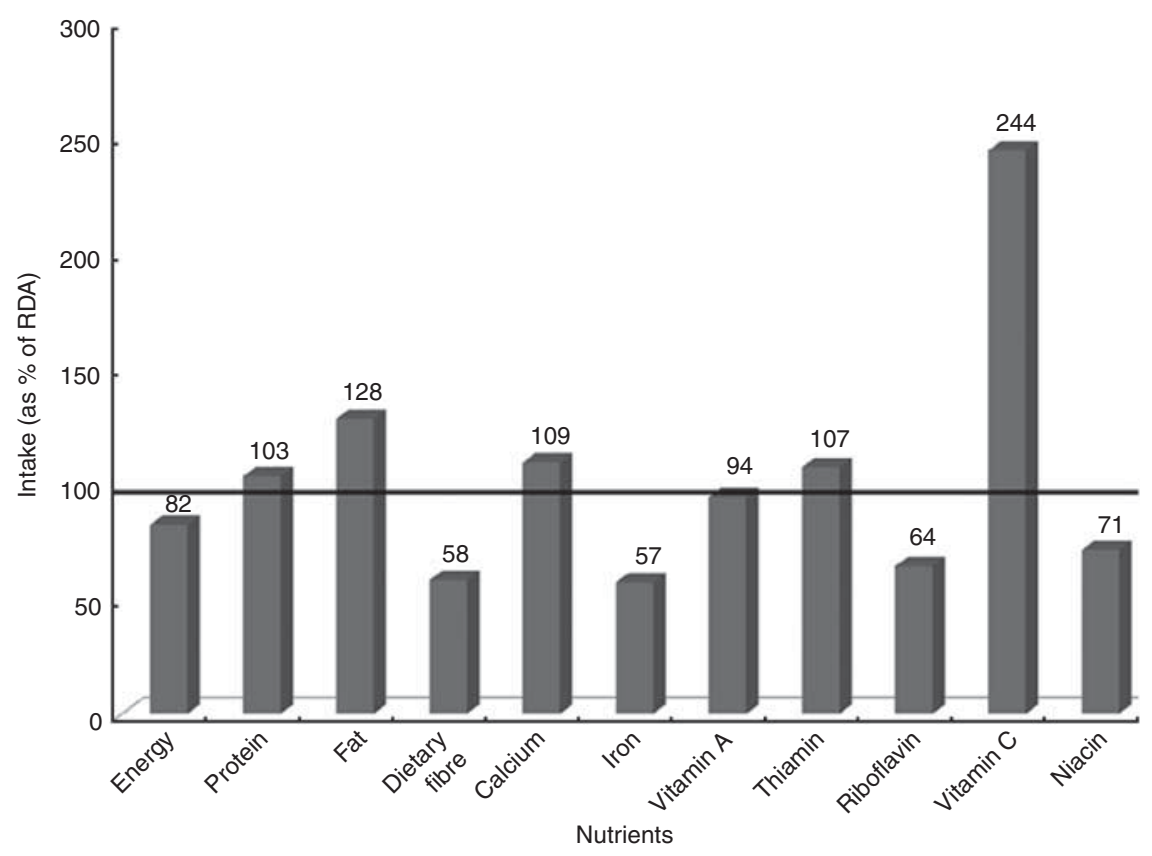

Fig. 3 Nutritional adequacy of the day's diet (mean intakes as a percentage of the day's RDA) for the study population; children, adolescents and adults ( $n$ 1027, aged 8 years and above) belonging to the middle and upper socio-economic classes in Mumbai, India. RDA as given by the Indian Council of Medical Research ${ }^{(11)}$ 
There is a lack of consensus in the literature on how much of the day's energy has to be provided by the breakfast meal to ensure correct nutrition. Indian recommendations for a balanced diet suggest that the day's energy intake should be equally divided between the three major meals of breakfast, lunch and dinner, with suitable adjustments being made if there are snacks consumed in between ${ }^{(15)}$. A study among 10-year-old children has shown that performance on a creativity test was better with a breakfast that provided $25 \%$ of the average daily requirements than with a breakfast that provided $10 \%$ of the daily energy requirements ${ }^{(16)}$. Italian guidelines suggest that breakfast should provide between $15 \%$ and $20 \%$ of the daily energy intake depending on whether between-meal snacks are consumed or not ${ }^{(17)}$. In view of all this, a meal meeting at least $25 \%$ of the day's RDA for energy was considered as nutritionally adequate in the present study.

Most breakfast-related studies in the literature have focused on the frequency of breakfast consumption and individuals have been classified into categories such as breakfast skippers, occasional breakfast eaters, frequent breakfast eaters, irregular breakfast eaters and regular breakfast eaters ${ }^{(12,13)}$. The findings of the present study, which examined breakfast skipping and nutrient adequacy of the breakfast meal, seem to suggest that individuals may not report skipping breakfast per se but the breakfast meal consumed has deficits with respect to energy and several other macro- and micronutrients. Although sufficient intakes of $\mathrm{Ca}$ were ensured due to consumption of milk at breakfast time, intakes of Fe and fibre from the breakfast meal were particularly low.

The present data also reveal age-specific features in breakfast eating patterns. Breakfast skipping was rampant among adolescents in the present study. The majority of schoolchildren and young adolescents were going to school with only a glass of milk or milk plus a milk foodbased drink. It is very likely that they leave home very early with insufficient time to have a substantial breakfast.

Lower breakfast skipping observed among adults aged $\geq 40$ years in the present study could be related to the inclusion of retired senior citizens in this age group. It is likely that such a group has a more systematic eating schedule and therefore a lower extent of breakfast skipping. However, nutritional inadequacy in the breakfast meal continued to be a feature observed in the sample's adult population as well.

\section{Implications of the study}

The present study highlights skipping of the breakfast meal by all age/gender groups in a fast-paced urban city like Mumbai, today. Likely reasons such as the lack of time for preparation and consumption of breakfast and the lack of appropriate knowledge on the nutritional importance of the first meal of the day need to be recognized. Development of 'nutrient-dense' yet easy-to-prepare breakfast foods that will ensure regular consumption of a healthy morning meal, despite time constraints, is the need of the hour. Breakfast foods that can be had 'on the move' while travelling to the place of work and school breakfast programmes are other solution options that need to be looked into if we are to address this fast-emerging problem of breakfast skipping in developing urban cities today. The findings of the present study, although specific to the study population in the city of Mumbai, India, has implications for urban population groups in most other rapidly growing economies across the globe that are experiencing similar lifestyle modifications.

\section{Acknowledgements}

Financial support for the study was provided by Kellogg India Private Limited. Both authors have no conflict of interest. M.S. was principal investigator of the project and responsible for project conceptualization. V.K. was the research associate responsible for data analysis. The authors appreciate the efforts of postgraduate diploma students in Applied Nutrition and Dietetics from Nirmala Niketan College of Home Science for data collection.

\section{References}

1. Kuczynski KJ, Cleveland LE, Goldman JD et al. (2006) Breakfast in America. FASEB J 20, A180.

2. Samuelson G (2000) Dietary habits and nutritional status in adolescents over Europe. An overview of current studies in the Nordic countries. Eur J Clin Nutr 54, Suppl. 1, S21-S28.

3. Cohen B, Evers S, Manske S et al. (2003) Smoking, physical activity and breakfast consumption among secondary school students in a southwestern Ontario community. Can J Public Health 94, 41-44.

4. Thompson-McCormick JJ, Thomas JJ, Bainivualiku A et al. (2010) Breakfast skipping as a risk correlate of overweight and obesity in school-going ethnic Fijian adolescent girls. Asia Pac J Clin Nutr 19, 372-382.

5. Smith KJ, Gall SL, McNaughton SA et al. (2010) Skipping breakfast: longitudinal associations with cardiometabolic risk factors in the Childhood Determinants of Adult Health Study. Am J Clin Nutr 92, 1316-1325.

6. Gajre NS, Fernandez S, Balakrishna N et al. (2008) Breakfast eating habit and its influence on attentionconcentration, immediate memory and school achievement. Indian Pediatr 45, 824-828.

7. National Institute of Nutrition (2004) Differences in attention-concentration, memory and school achievement of regular and irregular breakfast eaters and non-eaters. In Annual Report 2003-2004, pp. 27-29. Hyderabad: National Institute of Nutrition.

8. Livingstone MBE, Robson PJ \& Wallace JMW (2004) Issues in dietary intake assessment of children and adolescents. Br J Nutr 92, 2 Suppl., S213-S222.

9. Kuppuswamy B (1981) Manual of Socioeconomic Status (Urban). Delhi: Manasayan.

10. Gopalan C, Rama Sastri BV \& Balasubramanian SC (2004) Nutritive Value of Indian Foods. Hyderabad: National Institute of Nutrition. 
11. Indian Council of Medical Research (2010) Nutrient Requirements and Recommended Dietary Allowances for Indians. A Report of the Expert Group of the Indian Council of Medical Research 2010. Hyderabad, India: National Institute of Nutrition.

12. Preziosi P, Galan P, Deheeger M et al. (1999) Breakfast type, daily nutrient intakes and vitamin and mineral status of French children, adolescents and adults. J Am Coll Nutr 18, 171-178.

13. Yang R, Wang EK, Hsieh Y et al. (2006) Irregular breakfast eating and health status among adolescents in Taiwan. BMC Public Health 6, 295.
14. Timlin MT \& Pereira MA (2007) Breakfast frequency and quality in the etiology of adult obesity and chronic diseases. Nutr Rev 65, 268-281.

15. Bamji MS, Rao PN \& Reddy V (2003) Textbook of Human Nutrition, 2nd ed. New Delhi: Oxford \& IBH Publishing Co. Pvt. Ltd.

16. Pollitt E \& Mathews R (1998) Breakfast and cognition: an integrative summary. Am J Clin Nutr 67, issue 4, 804S-813S.

17. Marangoni F, Poli A, Agostoni C et al. (2009) A consensus document on the role of breakfast in the attainment and maintenance of health and wellness. Acta Biomed 80, 166-171. 